\title{
Risk factors for some tropical diseases in an African country
}

\author{
F.-M. E. Uzoka ${ }^{1 *} \mathbb{D}$, C. Akwaowo ${ }^{2}$, C. Nwafor-Okoli ${ }^{3}$, V. Ekpin ${ }^{4}$, C. Nwokoro ${ }^{5}$, M. El Hussein ${ }^{6}$, J. Osuji ${ }^{7}$, F. Aladi ${ }^{8}$, \\ B. Akinnuwesi ${ }^{9}$ and T. F. Akpelishi ${ }^{10}$
}

\begin{abstract}
Background: Often, non-clinical risk factors could affect the predisposition of an individual to diseases. Understanding these factors and their impacts helps in disease prevention and control. This study identified risk factors for malaria, yellow fever, typhoid, chickenpox, measles, hepatitis B, and urinary tract infection in a population in an African country.

Methods: Our study was an observational, correlational, and quantitative one that explored relationships among risk variables and disease prevalence - without modifying or controlling the variables. Data for this study was obtained through random sampling of a population of patients and physicians in the eastern/southern, western, and northern parts of Nigeria in 2015-2016. A total of 2199 patient consultation forms were returned by 102 (out of 125) physicians, and considered useful for analysis. Demographic data of patients, physicians, and diagnosis outcomes were analysed descriptively through frequency distributions, aggregate analysis, and graphs. The influence of risk factors on the disease manifestations (diagnosis outcomes) was determined using regression analysis.
\end{abstract}

Results: Our results show that living in a tropical climate is by far a major risk factor associated with tropical diseases (malaria: $\mathrm{t}=19.9$, typhoid: $\mathrm{t}=-3.2$, chickenpox: $\mathrm{t}=-6.5$ and typhoid: $\mathrm{t}=12.7$ ). The risk for contracting infections is relative to specific diseases; for example, contact with chickenpox infected person poses a high risk of contracting the virus $(t=41.8)$, while poor personal hygiene predisposes people to high risk of urinary tract infection $(t=23.6)$. On the other hand, urbanization and homelessness pose very low risks of disposing the individual to the diseases under consideration, while low fluid intake, lack of voiding, and wearing non-cotton underwear predispose individuals to few diseases.

Conclusion: The risk factors identified in our study exert differential and discriminating influences in the causation, predisposition, and transmission of these disease studied. It is recommended that significant effort be devoted by governments in the tropics to the mitigation of these modifiable risk factors. The most important strategy to mitigate the occurrence of these risk factors will be improving the living conditions of people and the provision of social protection measures to reduce the occurrence and burden of these diseases.

Keywords: Risk factor, Infectious diseases, Tropical diseases, Communicable diseases and sub-Saharan Africa

*Correspondence: fuzoka@mtroyal.ca

1 Dept. of Math and Computing, Mount Royal University, 4825 Mt Royal Gate SW, Calgary, ABT3E 6K6, Canada

Full list of author information is available at the end of the article

\section{Background}

Tropical diseases are a diverse group of infectious diseases that are endemic in tropical and subtropical regions. They are caused by pathogens like viruses, bacteria, and parasites. Unfortunately they tend to be 'neglected' as they typically affect people in low socioeconomic classes, 
with poor sanitary and housing conditions as well as people in areas that have difficult access to health services [1]. Tropical diseases represent a significant public health problem and have high mortality rates especially if left untreated [1,2]; as such, tropical diseases have drawn the attention of international health organizations.

Due to globalization of trade and increased travel to and from endemic regions tropical diseases are no longer localized in tropical regions [3]. The difficulty associated with early diagnosis is of particular concern because tropical diseases can present with overlapping and confusable symptoms. Understanding the symptoms, risk factors, diagnosis, and treatments of these diseases is of global importance as they can give further insights into their differential diagnoses. Tropical diseases present a diagnostic challenge to physicians, especially in non-endemic regions. An understanding of the various risk factors for tropical diseases can give improved insights into their differential diagnoses. Besides, research has shown that risk factors for a particular disease could change over time. It has been established that a substantial epidemiological shift occurred in the contribution of different risk factors to disease burden within 1990-2010 [4].

About two decades ago, communicable, maternal, perinatal, and nutritional disorders explained $43.9 \%$ of all causes of death and disability, while non-communicable causes explained $40.9 \%$ [5]. This picture has changed drastically; in 2017, the leading causes of death and disability worldwide had moved from communicable towards non-communicable diseases [6]. Evidence shows that between 1990 and 2017, early death from enteric infections, respiratory infections and tuberculosis, and maternal and neonatal disorders dropped, with the greatest declines in the least developed countries [6]. However, these broad global disease patterns mask enormous regional and geographical variation in health risks [7]. In sub-Saharan Africa, risks such as childhood underweight, household air pollution, and micronutrient deficiency continue to cause a disproportionate health burden [6].

Malaria is one of the most common tropical diseases with about 3.2 billion of the world's population at risk of the disease [8]. An efficient system for malaria transmission requires strong interaction between the hosts, the ecosystem and infected vectors as it is spread through the bites of infected mosquitoes $[9,10]$. Another tropical disease of significant public health importance is typhoid fever, also called enteric fever. It is a systemic bacterial illness transmitted from person to person via the fecaloral route [10]. Several factors have been linked to risk of having typhoid fever including domestic use of contaminated water, poor waste management, and living in urban slums [11-13]. Similar to malaria, yellow fever which is endemic in tropical and subtropical areas of Africa and South America is also spread through the bite of infected mosquitoes. Hence its risk factors are related to factors that favour vector proliferation and those that reduce host immunity [14-17].

Several other diseases including measles, varicella zoster, urinary tract infections and hepatitis $B$ can present with confusable symptoms. Although these are not limited to the tropics, they sometimes present atypically or with increased severity in tropical regions and are therefore a cause for concern. For example, Varicella zoster, which typically causes mild disease in children [13, 14], occurs at a later age in the tropics where it causes a more severe and sometimes fatal disease [15]. Also, several practices predispose those in some African countries to a higher risk of Hepatitis B which is a blood borne disease. Examples of these practices include traditional scarification and tattooing, circumcision by traditional healers, and female genital mutilation. This is because instruments with poor standard sterilization measures are typically used and reused [16].

The risk factors for tropical diseases are different from those of non-communicable diseases (NCDs) in that the risk of non-communicable diseases are mainly related to individual lifestyle and often reflect the choices of persons such as physical inactivity, high calorie diets, alcohol use and cigarette smoking [6]. For communicable diseases, however, an assessment of the risk factors helps to narrow down from the array of confusable signs and symptoms, bringing to focus the index disease for diagnosis. Assessing risk factors for diseases also gives the opportunity for risk factor modification in order to prevent future recurrences of these diseases [17]. Understanding these risk factors at individual and population levels will lead to informed policy, decision making, and planning accurate interventions.

The purpose of this study was to identify risk factors for malaria, yellow fever, typhoid, chickenpox, measles, hepatitis B and urinary tract infection (UTI) in Nigeria, the most populous African country. We analysed risk factors associated with some tropical diseases that are prevalent in the country. We also determined the prevalence of these diseases in the population based on diagnoses.

\section{Methods}

Study design

Our study was an observational, correlational, and quantitative (analytical) one that sought to describe and discover relationships among risk variables (independent variables) and disease prevalence (dependent variable) - without modifying or controlling the variables. We assessed the effects of exposure of the individual to the following non-clinical risk factors on disease prevalence 
(inferred from patient diagnosis results): low socioeconomic status (Lwsocec), immigration (Immig), tropical climate (Tropclim), urbanization - newcomers (Urbanzatn), street vendor (Strtvend), sewage contamination (Swgcont), poor personal hygiene (Popershy), overcrowding (Ovrcrwd), homelessness (Hmlsness), travel to endemic region (Trendreg), skin puncture procedure (Sknpunproc), direct contact with infected persons (Continfect), low fluid intake (Lowfliud), non-cotton underwear (Noncotund), and lack of voiding (Lackvoid).

Our sampling method was random from a population of patients in the eastern/southern, western, and northern parts of Nigeria. The patients volunteered for the study at the reception desks of their physicians, were randomly selected from hospitals and clinics in selected cities in Nigeria. The cities were selected based on convenience of access.

\section{Data collection}

Data for this study was obtained through patient diagnosis forms, distributed to physicians in Nigeria between 2015 and 2016. Twenty patient consultation forms were distributed to each of 125 physicians, who were randomly selected from northern, western and eastern/ southern Nigeria. The patient data collection form had five sections: Section A contained demographic information about the patient and the attending physician; Section B obtained information about clinical presentations (symptoms) and risk factors based on patient consultation; Section $C$ gave the physician the opportunity to indicate suspected diseases (hypotheses); Section D contained further investigation information, while Section E showed the final diagnosis. The final diagnoses were arrived at through further diagnostic tests conducted on the patients to determine the actual disease(s) and their intensity levels. The survey instrument was pilot tested on a subset of participants. These pilot data were analysed using the principal component analysis to reduce data dimensionality and eliminate redundant variables.

Ethical clearance was sought and obtained from Mount Royal University Human Research Ethics Board. Patient written consent was sought before the utilization of the data collection form during patient consultation. All patients from the population were included in the study, in so far as they could provide consent or assisted consent plus assent (for children and other vulnerable patients). The physicians that were included in the study were general practitioners and family physicians. Specialist physicians and physicians in training were excluded from the study. There was no age or sex restriction regarding patients who participated in the study; however, to ensure that minors were protected from undue influence, only minors (ages $0-17$ ) whose parents consented to participation in the study were included. In addition, a minor's assent was required to participate in the study. Data collection was entirely anonymous, and completed forms were returned without any respondent's or patient's identification information.

\section{Data analysis}

The Statistical Package for Social Sciences (SPSS) version 20.0 was utilized in the analysis of data. Demographic data of patients, physicians, and diagnosis outcomes were analysed descriptively through frequency distributions, aggregate analysis, and graphs. We conducted multiple linear regression analysis to determine the impact of risk (non-clinical) factors on the prevalence of tropical diseases under consideration.

A weighting of the disease prevalence by the physicians was carried out using the aggregation formula adapted from Uzoka and Ndzinge (2009) [18]:

$$
\text { Weighted Prevalence }=\frac{\sum_{i=1}^{5} w_{i} p_{i}}{5}
$$

where $w_{i}$ is the weight assigned to $i^{\text {th }}$ level of intensity of attack of a given disease. The intensity ranges from very low $\left(w_{i}=1\right)$ to very high $\left(w_{i}=5\right)$; Pi is the percentage of patients diagnosed with the given disease, with intensity of attack i. Note that some patients were diagnosed with multiple diseases at different levels of intensity of attack. The prevalence percent is computed relative to all the weighted prevalence values.

SPSS also computes the collinearity statistics (the tolerance and variance inflation factor [VIF]) to determine if two variables are near perfect linear combinations of one another. As the degree of collinearity increases, the linear regression model estimates of the coefficients become unstable. The "tolerance" is an indication of the percent of variance in the predictor that cannot be accounted for by the other predictors, hence very small values indicate that a predictor is redundant. Ideally the tolerance should be greater than 0.5 , while the VIF should be 5 or less.

\section{Results}

A total of 2159 diagnosis forms out of 2500 (86.36\%) were returned and considered useful for analysis. Table 1 shows the demographic information on the patients, the physicians who conducted the diagnosis and the weather season when the patient consultation/diagnosis was conducted. The sample consisted of $52.6 \%$ females and $47.4 \%$ males, who were mostly below 40 years $(76.5 \%)$, while most of the diagnosis (63.4\%) were carried out by experienced physicians (over 5 years). The levels of experience of the physicians point to their ability to clearly understand the dynamics of tropical diseases. The final 
Table 1 Demographic

\begin{tabular}{lll}
\hline & Frequency & Percent \\
\hline Sex & & \\
Male & 1038 & 47.4 \\
Female & 1150 & 52.6 \\
Patient age (years) & & \\
$\leq 10$ & 438 & 19.9 \\
$10-20$ & 401 & 18.2 \\
$21-30$ & 555 & 25.2 \\
$31-40$ & 290 & 13.2 \\
$41-50$ & 288 & 13.1 \\
$51-60$ & 111 & 5.0 \\
$>60$ & 116 & 5.3 \\
Diagnosing physician's experi- & & \\
ence & & \\
$<5$ & 37 & 36.6 \\
$5-10$ & 26 & 25.7 \\
$11-15$ & 13 & 12.9 \\
16-20 & 3 & 3.1 \\
$>$ 20 & 22 & 21.7 \\
Season & & \\
Rainy & 381 & 17.3 \\
Harmattan & 655 & 29.8 \\
Dry & 1163 & 52.9 \\
\hline
\end{tabular}

diagnosis outcomes were arrived at through further tests that were conducted on the patients to determine the actual disease(s) and their intensity levels. Sixty percent of the diagnoses were conducted in the dry season, while the rest were either in the rainy or harmattan seasons. There was a shortfall of 11 in the patient sex, resulting from the sex box of some forms not checked by some physicians. Also, note that the diagnosing physician's experience was only obtained from the patient's diagnosis form as the data was not aggregated by diagnosing physician.

Table 2 shows the weighted and unweighted disease prevalence as diagnosed by the physicians. The highest unweighted prevalence being malaria (61.3\%), UTI, (19.1\%), typhoid (18.3\%). However, the prevalence of the diseases differed significantly when weighted. Note that some patients were diagnosed with multiple diseases at different levels of intensity of attack. The prevalence percent was computed relative to all the weighted prevalence values. Table 2 shows the overall prevalence and intensities.

The results indicate that malaria was the most commonly diagnosed disease, followed by UTI, and typhoid. Malaria also with had the highest intensity of 14.1 moderate, 25.1 high and 10.7 very high. A total of $61.32 \%$ of the patients were diagnosed with malaria; $49.9 \%$ of which had moderate to very high intensity of attack, while $11.4 \%$ had low intensity. The second and third in level of prevalence were UTI and typhoid fever, with intensity weights of 14.32 and 11.50 respectively.

\section{Regression analysis}

Table 3 shows the regression statistics. The risk factors (predictor) were regressed against the intensity of attack of each disease (outcome). The risk factors are abbreviated (first column of Table 3 because of table space and formatting constraints), while a key is provided at the bottom of the table to show the full meanings of the abbreviations. The collinearity statistics (Tolerance [Tol] and variance inflation factor [VIF]) show good levels of tolerance $[>0.2]$ and variance inflation factor (VIF) $[<5]$ for most of the predictors, relative to each disease (except for low fluid and lack of void, both of which exhibit Tol of 0.18 and 0.2 respectively). The predictive power of the model $\left(R^{2}\right.$, adjusted $\left.R^{2}\right)$ was generally low.

Table 2 Disease prevalence based on diagnosis

\begin{tabular}{|c|c|c|c|c|c|c|c|c|}
\hline \multirow[t]{2}{*}{ Disease } & \multicolumn{6}{|c|}{ Intensity of attack } & \multirow{2}{*}{$\begin{array}{l}\text { Weighted } \\
\text { prevalence }\end{array}$} & \multirow{2}{*}{$\begin{array}{l}\text { Prevalence } \\
\text { percent }\end{array}$} \\
\hline & $\begin{array}{l}\text { Percent } \\
\text { diagnosed }\end{array}$ & Very low & Low & Moderate & High & Very High & & \\
\hline Malaria & 61.30 & 3.40 & 8.00 & 14.10 & 25.10 & 10.70 & 43.12 & $47.91 \%$ \\
\hline Typhoid & 18.30 & 0.80 & 3.00 & 9.00 & 3.70 & 1.70 & 11.42 & $12.69 \%$ \\
\hline Chicken Pox & 7.20 & 0.10 & 0.20 & 4.60 & 2.10 & 0.30 & 4.84 & $5.38 \%$ \\
\hline Measles & 1.30 & 1.20 & 0.10 & 0.00 & 0.00 & 0.00 & 0.28 & $0.31 \%$ \\
\hline Hepatitis B & 3.30 & 1.00 & 0.40 & 1.70 & 0.10 & 0.10 & 1.56 & $1.73 \%$ \\
\hline Yellow Fever & 0.70 & 0.10 & 0.20 & 0.10 & 0.40 & 0.00 & 0.48 & $0.53 \%$ \\
\hline UTI & 19.10 & 3.10 & 0.50 & 0.90 & 7.80 & 6.70 & 14.30 & $15.89 \%$ \\
\hline Other & 18.40 & 0.00 & 2.70 & 3.20 & 7.50 & 5.00 & 14.00 & $15.56 \%$ \\
\hline
\end{tabular}


Table 3 Regression statistics

\begin{tabular}{|c|c|c|c|c|c|c|c|c|c|c|c|c|c|c|c|c|c|c|}
\hline \multirow{4}{*}{$\begin{array}{l}\mathrm{R}^{2} \\
\text { Adjusted } \mathrm{R}^{2}\end{array}$} & \multirow{2}{*}{\multicolumn{2}{|c|}{$\begin{array}{l}\text { Malaria } \\
0.491\end{array}$}} & \multirow{2}{*}{\multicolumn{2}{|c|}{$\begin{array}{l}\text { Typhoid } \\
0.366\end{array}$}} & \multirow{2}{*}{\multicolumn{2}{|c|}{$\begin{array}{l}\text { Chk Pox } \\
0.647\end{array}$}} & \multirow{2}{*}{\multicolumn{2}{|c|}{$\begin{array}{l}\text { Measles } \\
0.023\end{array}$}} & \multirow{2}{*}{\multicolumn{2}{|c|}{$\begin{array}{l}\text { Hepatitis B } \\
0.033\end{array}$}} & \multirow{2}{*}{\multicolumn{2}{|c|}{$\begin{array}{l}\text { Yellow } \\
\text { Fever } \\
0.037\end{array}$}} & \multirow{2}{*}{\multicolumn{2}{|c|}{$\begin{array}{l}\text { UTI } \\
0.465\end{array}$}} & \multirow{2}{*}{\multicolumn{2}{|c|}{$\begin{array}{l}\text { Others } \\
0.286\end{array}$}} & \multirow[t]{4}{*}{ Tol } & \multirow[t]{4}{*}{ VIF } \\
\hline & & & & & & & & & & & & & & & & & & \\
\hline & \multicolumn{2}{|l|}{0.487} & \multicolumn{2}{|l|}{0.362} & \multicolumn{2}{|l|}{0.644} & \multicolumn{2}{|l|}{0.016} & \multicolumn{2}{|c|}{0.026} & \multicolumn{2}{|l|}{0.030} & \multicolumn{2}{|l|}{0.461} & \multicolumn{2}{|l|}{0.281} & & \\
\hline & $t$ & $p$ & $t$ & $p$ & $t$ & $p$ & $t$ & $p$ & $t$ & $p$ & $T$ & $p$ & $t$ & $p$ & $t$ & $p$ & & \\
\hline Lwsocec & 7.9 & 0.00 & 0.2 & 0.00 & -6.9 & 0.00 & 1.5 & 0.13 & 0.9 & 0.36 & -2.8 & 0.01 & -1.3 & 0.19 & 6.8 & 0.00 & 0.56 & 1.78 \\
\hline Immig & 7.8 & 0.00 & 7.2 & 0.81 & 15.1 & 0.00 & -1.2 & 0.23 & -3.0 & 0.00 & 0.3 & 0.79 & 1.8 & 0.07 & -10.6 & 0.00 & 0.64 & 1.57 \\
\hline Tropclim & 19.9 & 0.00 & -3.2 & 0.00 & -6.5 & 0.00 & -4.3 & 0.00 & -3.6 & 0.00 & -3.1 & 0.00 & 12.7 & 0.00 & -4.5 & 0.00 & 0.82 & 1.2 \\
\hline Urbanzatn & 1.1 & 0.28 & 3.4 & 0.00 & -6.7 & 0.00 & -1.7 & 0.09 & -2.9 & 0.00 & 1.0 & 0.31 & 1.5 & 0.14 & 2.9 & 0.00 & 0.53 & 1.8 \\
\hline Strtvend & -10.0 & 0.00 & 10.7 & 0.00 & 6.8 & 0.00 & -0.5 & 0.65 & -3.7 & 0.00 & 7.9 & 0.00 & -2 & 0.01 & 2.6 & 0.01 & 0.69 & 1.4 \\
\hline Swgcont & 4.5 & 0.00 & 10.7 & & & & 0.0 & & 2.7 & & & 0.05 & & & 3.6 & & 0.46 & 2.1 \\
\hline Popershy & -0.6 & 0.55 & -3.5 & 0.00 & -2.4 & 0.01 & -3.5 & 0.00 & -0.3 & 0.76 & 0.0 & 0.99 & 23.6 & 0.00 & 0.4 & 0.67 & 0.48 & 2.0 \\
\hline Ovrcrwd & -5.2 & 0.00 & 3.1 & 0.00 & 5.6 & 0.00 & 2.3 & 0.02 & 2.1 & 0.03 & 1.1 & 0.26 & -1.8 & 0.07 & 11.2 & 0.00 & 0.65 & 1.54 \\
\hline Hmlsness & 0.3 & 0.75 & 7.6 & 0.00 & -0.1 & 0.88 & -0.3 & 0.79 & -2.2 & 0.03 & -0.2 & 0.83 & -5.0 & 0.00 & -3.2 & 0.00 & 0.57 & 1.74 \\
\hline Trendreg & 11.0 & 0.00 & -10.5 & 0.00 & -7.3 & 0.00 & -2.3 & 0.02 & 1.4 & 0.17 & -0.9 & 0.38 & -5.2 & 0.00 & 6.3 & 0.00 & 0.75 & 1.3 \\
\hline Sknpunproc & -3.2 & 0.00 & 0.3 & 0.00 & 3.6 & 0.00 & -0.5 & 0.65 & 4.0 & 0.00 & -1.4 & 0.15 & -3.3 & 0.00 & -10.0 & 0.00 & 0.83 & 1.2 \\
\hline Continfect & -19.9 & 0.00 & -12.8 & 0.76 & 41.8 & 0.00 & -0.8 & 0.41 & 1.3 & 0.21 & -1.9 & 0.06 & -4.3 & 0.00 & 10.2 & 0.00 & 0.66 & 1.5 \\
\hline Lowfliud & -12.4 & 0.00 & 6.2 & 0.00 & 2.8 & 0.01 & 0.1 & 0.93 & 1.2 & 0.24 & -0.4 & 0.68 & -2.6 & 0.01 & 0.8 & 0.45 & 0.18 & 5.5 \\
\hline Noncotund & -10.9 & 0.00 & -3.6 & 0.00 & -1.1 & 0.25 & -0.3 & 0.79 & -1.0 & 0.30 & -1.8 & 0.07 & 8.6 & 0.00 & -3.1 & 0.00 & 0.66 & 1.52 \\
\hline Lackvoid & 12.1 & 0.00 & -8.1 & 0.00 & -0.9 & 0.39 & -0.2 & 0.86 & -0.9 & 0.34 & -0.1 & 0.89 & 10.9 & 0.00 & -2.8 & 0.00 & 0.20 & 5.0 \\
\hline
\end{tabular}

Key: low socioeconomic status (Lwsocec), immigration (Immig), tropical climate (Tropclim), urbanization - newcomers (Urbanzatn), street vendor (Strtvend), sewage contamination (Swgcont), poor personal hygiene (Popershy), overcrowding (Ovrcrwd), homelessness (Hmlsness), travel to endemic region (Trendreg), skin puncture procedure (Sknpunproc), direct contact with infected persons (Continfect), low fluid intake (Lowfliud), non-cotton underwear (Noncotund), and lack of voiding (Lackvoid)

The t-values show that the risk factors do significantly predispose individuals to infectious diseases, especially malaria, typhoid, chicken pox, and UTI. Table 4 provides a visual representation of the risk levels associated with each risk factor. This is based on the t-values in Table 3; the key to the decision on the level of risk is shown beneath Table 4 . Living in a tropical climate is evidently a major risk factor associated with tropical diseases. Being a street vendor predisposes people to infection; so is overcrowding and traveling to endemic regions. It is also

Table 4 Disease-risk factor relationships

\begin{tabular}{|c|c|c|c|c|c|c|c|c|}
\hline & Malaria & Typhoid & Chicken Pox & Measles & Hepatitis B & Yellow Fever & UTI & Others \\
\hline Lwsocec & * & $* *$ & * & & & * & & * \\
\hline Immig & * & & $* *$ & & * & & & $* *$ \\
\hline Tropclim & $* *$ & * & * & * & * & * & * & $*$ \\
\hline Urbanzatn & & * & * & & * & & & * \\
\hline Strtvend & $* *$ & $*$ & * & & * & * & * & * \\
\hline Swgcont & * & $* *$ & $* *$ & & * & & $* *$ & * \\
\hline Popershy & & $* *$ & * & * & & & $* * *$ & \\
\hline Ovrcrwd & * & $*$ & * & * & * & & & $* *$ \\
\hline Hmlsness & & * & & & * & & * & $*$ \\
\hline Trendreg & $* *$ & * & * & * & & & * & * \\
\hline Sknpunproc & * & $* *$ & * & & * & & * & * \\
\hline Continfect & $* *$ & & $* * *$ & & & & * & $* *$ \\
\hline Lowfliud & $* *$ & $* *$ & $*$ & & & & * & \\
\hline Noncotund & $* *$ & $*$ & & & & & * & * \\
\hline Lackvoid & $* *$ & * & & & & & $* *$ & * \\
\hline
\end{tabular}


instructive to note that some factors pose higher risks than others; for example, contact with an infected person poses a high risk of chicken pox infection $\left(\mathrm{t}=41.8\left[{ }^{[* * *}\right]\right)$, while poor personal hygiene predisposes people to high risk of urinary tract infection $(t=23.6[* * *])$. On the other hand, urbanization and homelessness, pose very low risks [*] across all the diseases, while low fluid intake, lack of void, and wearing non-cotton underwear only predispose individuals to few diseases ( 3 in each case).

Key

\begin{tabular}{lll}
\hline Risk Level & Condition & Symbol \\
Low & $2 \leq t<10$ & $*$ \\
Medium & $10 \leq t \leq 20$ & $* *$ \\
High & $t>20$ & $* * *$ \\
\hline
\end{tabular}

\section{Discussion}

This study aimed to identify risk factors for selected diseases in Nigeria, the most populous African country. We analysed risk factors associated with some tropical diseases and determined the prevalence of these diseases in the population based on diagnoses. We found the diseases with the highest unweighted prevalence to be malaria (61.3\%), UTI (19.1\%), typhoid (18.3\%); however, the prevalence of the diseases differed significantly when weighted. Regression analysis confirmed that these risk factors do significantly predispose individuals to infectious diseases, especially malaria, typhoid, chickenpox, and UTI. Furthermore, some factors posed higher risks than others; for example, contact with an infected person poses a high risk of chickenpox infection, and poor personal hygiene predisposes people to high risk of urinary tract infection. On the other hand, urbanization and homelessness pose very low risks across all the diseases, while low fluid intake, lack of voiding, and wearing noncotton underwear predispose individuals to few diseases.

The study focused on epidemic prone and priority diseases in Nigeria [19, 20], including malaria, typhoid, chicken pox, UTI, measles, yellow fever and hepatitis B. These tropical diseases are diseases of public health importance in Nigeria. Surveillance of these diseases of public health importance is captured by using the Integrated Disease Surveillance and Response (IDSR) [21]. IDSR is a framework implemented to improve detection and response to the primary causes of morbidity and mortality in African countries. However, there have been challenges to the implementation of this policy, one of which is the limited capacities of personnel to identify and report IDSR priority diseases [22, 23]. This underscores the importance of our study to enhance the capacity of health workers to identify and report these diseases for adequate surveillance.
Our results indicate that malaria, UTI, and typhoid are prevalent in Nigeria and agree with previous works done on disease prevalence in the country $[1,24,25]$. These diseases remain diseases of major public health importance in Nigeria. Although UTI is not classified as a tropical disease, the burden of the disease in Nigeria and the fact that some of the causative organisms could be tropical led to its inclusion in the index study. It has been shown previously that malaria and typhoid are at the top of the chart of the most overwhelming health problems facing the tropical and subtropical African countries, with malaria alone claiming 213 million cases and over 380,000 deaths per year [26]. It is reported that a $1{ }^{\circ} \mathrm{C}$ increase in maximum temperature in a given month was related to a 15 and $19 \%$ increase in malaria incidence in the same and subsequent month, respectively [27].

Similar to findings in our study, a study in central Vietnam linked low socioeconomic class to be an important risk factor for malaria. It was opined that this was possible because of poorer housing conditions increasing their exposure to infective bites within their villages and the fact that those of lower socioeconomic class were more likely to make regular visits to and even sleep in forests [28]. Poverty can therefore be said to be an underlying risk factor, linking and potentiating the different risk factors for malaria [29]. Higher socioeconomic status is associated with better housing structures, the situation of houses in better environments, the ability to afford prevention methods, and better refuse collection, among others, all of which reduce the risk of malaria infection [30].

In our study, the majority of the cases of malaria diagnosed was high intensity, and for typhoid, moderate intensity. This highlights the public health significance of malaria as an endemic disease in the study areas. The majority of the physicians who conducted the study were urban-based; this could explain the high intensity and transmission. It has been observed that contrary to the expectation that urbanization should reduce malaria transmission, the disease still persists in African cities, in some cases at higher levels than in nearby rural areas. The explanation was suggested to be an adaptation of malaria vector species to the urban environment [30].

The study also highlights typhoid as a major public health disease. Several factors have been linked to risk of having typhoid fever. Studies have linked domestic use of contaminated water to the incidence of enteric fever [10, $11]$. This is important in Nigeria as only $64.1 \%$ of the population have household members with improved access to drinking water and the percentage of household members using improved sanitation facilities which are not shared is $35.1 \%$ [31]. These factors predispose people to use fecally-contaminated water for food preparation and 
drinking, thus placing them directly at risk for typhoid fever. In addition, consumption of raw vegetables, meat, seafood, and milk, which are often contaminated with excreta of an infected person, has been shown to increase the risk of typhoid fever [11,32]. This can be linked to the consumption of street foods [33]. Akuu et al. reported that those who ate out in food stalls were 6.9 times more likely to have typhoid fever [34]. This finding was attributed to poor hygiene maintained by commercial food vendors as they have little to no regulation in most tropical regions [34, 35].

This study revealed some critical risk factors linked to the diseases studied. Living in a tropical climate is evidently a major risk factor associated with tropical diseases in Nigeria. This is a risk factor that is clearly non-modifiable except by migration; therefore, this can be termed as an overarching risk factor that sets the stage for interplay of the other risk factors. This finding can be understood from the standpoint of the lifecycle of the causative agents of the diseases where warm climate plays a major role in the reproduction and propagation of the pathogens. It has been shown that temperature and moisture variables are the most important drivers for some tropical diseases like malaria [27, 36]. Rapid urbanization seen in our cities with attendant destruction of the natural environment is associated with this risk factor $[37,38]$. Thus, poor urban structures with the creation of urban slums expose people to more pathogens, creating a vicious cycle of poverty and disease.

Another important risk factor is travel from a nonendemic to an endemic region, which increases the risk of contracting malaria as individuals with no natural immunity are inevitably exposed to the disease in these areas [39]. The travellers are also at risk of eating unsafe foods and drinking contaminated water, underscoring the importance of abiding by food safety regulations.

We also found that the factors that measured the level of exposure to infectious agents were important predictors for diseases. It was found that being a street vendor predisposes people to infection. This finding is expected because this risk factors enhances contact with disease pathogens and possible disease establishment. As observed in this study, contact with an infected person increased the risk of chickenpox by about 42 times. In the case of UTI, poor personal hygiene leads to exposure and prolonged contact with infectious agents. Poor hygiene therefore increased the risk of UTI up to about 24 times as seen in this study. A previous study also reported the link between poor genital hygiene and development of UTIs [40].

It is also important to note that the levels of risk factors in our study were found to vary, with some risk factors predisposing individuals to more diseases than others.
Among the factors with low-risk levels were urbanization, low fluid intake, lack of voiding, and wearing non-cotton underwear predisposing individuals to few diseases. However, we were surprised to observe that homelessness also predisposed individuals to only few diseases. Previous studies have shown that homelessness predisposes individuals to a host of diseases [41-43]. We can attempt to explain this variation by looking at the geographical location where these studies were conducted.

Many of these diseases are preventable and/or treatable through specific interventions [44]. Although various pathogens cause the vast array of tropical diseases, the risk factors that are commonly seen include low socioeconomic status, poverty and overcrowding. With globalization and urbanization, these risk factors are compounded as the urban slums are characterized by homeless people, street vending, poor personal hygiene, close contact with infected persons as well as poor sanitary conditions. With progressive underinvestment in infrastructure and amenities, there are disproportionate levels of poverty and poor living conditions $[45,46]$. Compounding these is poor access to affordable healthcare services in Nigeria.

Access to health services especially for the low socioeconomic class is poor, with only about $5 \%$ of Nigerians covered by the national health insurance scheme under the NHIS [47]. This leaves a majority of the urban poor without access to preventive health care and continuous exposure to these risk factors compound the existing poor health status leading to worsening morbidity and mortality. In addition, health resource allocation is in favour of secondary and tertiary care, while primary health care which attends to a majority of the people are poorly funded. This leads to people seeking primary care at the secondary and tertiary centres. Therefore, it is critical to reorient the health sector towards promoting health, especially at the primary care level, by strengthening the PHC delivery system and reducing health inequities as espoused by the WHO. This would improve access to preventive health services, thereby curbing the spread of some of these tropical diseases.

\section{Study implications}

The majority of the risk factors studied here could be termed as proximal determinants of health. Interestingly, we have noted that they are largely modifiable. Although not traditionally classified as modifiable in communicable disease epidemiology, we make a case for treating these risk factors as modifiable. This is pertinent against the background of the evidence that drivers of poor health can be reduced by addressing the social causes of poor health. Therefore, improving the living conditions of people including; urban infrastructure and governance, early 
childhood development and education, employment conditions, and social protection measures, will improve populations' health and well-being. Addressing the social determinants related to tropical diseases is a reasonable public health intervention for disease control and at the same time, is a prerequisite for confronting inequities in health [7]. Further studies on how homelessness influence disease acquisition in tropical settings, especially in sub-Saharan Africa, are required to understand the true picture of the risk factor in tropical countries.

\section{Limitations}

We acknowledge the limitations of this study as follows: Some key tropical diseases that are common in Sub Saharan Africa were not included in the study, including tuberculosis and upper and lower respiratory tract infections. Also, our study focused solely on Nigeria as a geographical entity for data collection. Although this limits the generalizability of study, we expect that our findings can be extrapolated to other regions of Africa and the tropics, since the risk factors focused on are similar in these areas. Additionally, we recognize that variables included in this study are limited to mostly environmental (nonmedical) circumstances. A future study will include personal(medical) risk factors, such as blood pressure, high cholesterol level, genetic conditions and allergies.

\section{Recommendations}

There is a need to reduce inequities and inequalities in society by addressing the poverty and low socioeconomic status of the urban populations. We recommend that significant effort be put into mitigating some of these factors, which are low socioeconomic class, homelessness, overcrowding as well as the negative effects of urbanization. This can be done by government strategies targeting improving living conditions, provision of potable water and sanitation facilities, and provision of housing. Furthermore, poverty, which was seen to be an underlying factor potentiating these risk factors, should be addressed by the creation of job opportunities for people both in the public and private sector.

At the individual level, poor hygiene, poor voiding, wearing of non-cotton underwear, and low fluid intake at the individual level can be achieved through engagement at the community level with various public health interventions targeted at behavioral changes. Public Health Specialists and other health officials have the tasks of engaging the communities to provide health education, raising awareness of these risk factors, and its effect on health to effect the necessary behavioral change.

Finally, the federal ministry of health should ensure vaccination and chemoprophylaxis of non-immune individuals migrating to or visiting endemic regions to prevent and reduce the severity of these tropical diseases. The findings in the present study underscore the complexity and risk factors associated with the transmission of tropical diseases and further explains why people exposed to the risk factors mentioned have higher chances of contracting some of the tropical diseases.

\section{Policy recommendations}

Policies that address poverty and poor housing conditions in the country should be instituted. These could be done by creating affordable housing and by instituting employment programmes for the poor and most vulnerable. Furthermore, policies that mitigate indiscriminate drilling of boreholes should be enacted in order to prevent use of contaminated water.

Based on the study findings, our ultimate goal is to attempt to develop the framework for a soft computing system, which will take into consideration tropical disease risk factors and tropical disease symptoms in order to facilitate easier and more efficient differential diagnosis of these diseases.

\section{Conclusion}

The processes involved in diagnosing and differentiating tropical disease conditions by medical practitioners are complex and may sometimes be confusing because of overlap and vagueness in symptoms presented by the different conditions. Furthermore, most of these conditions share same predisposing or risk factors. This builds the case for the exploration and understanding of the impact of different risk factors on the populations' predisposition to these conditions.

Of the studied infectious diseases, malaria, UTI and typhoid fever were the most significant in terms of morbidity. The risk factors discussed and explored in this study also significantly influence the spread of these conditions, hence the need for evidence-based decisions to control these diseases.

The findings of this study have made a case for treating the risk factors for communicable diseases as being modifiable and linked directly with social determinants of health. Action is required at governmental, community, and individual levels to improve and mitigate these risk factors. Interventions by the order government to improve the social determinants of health associated with living conditions are key to reducing these communicable diseases' risk factors. To this end, concerted efforts should be made by governments towards the implementation of policies to reduce inequities and inequalities associated with the social determinants of health in the country.

\section{Abbreviations}

NCD: Non-communicable disease; UTI: Urinary tract infection; SPSS:

Statistical Package for Social Sciences; VIF: Variance inflation factor; IDSR 
Integrated Disease Surveillance and Response; Lwsocec: Low socioeconomic status; Immig: Immigration; Tropclim: Tropical climate; Urbanzatn: Urbanization - newcomers; Strtvend: Street vendor; Swgcont: Sewage contamination; Popershy: Poor personal hygiene; Ovrcrwd: Overcrowding; Hmlsness: Homelessness; Trendreg: Travel to endemic region; Sknpunproc: Skin puncture procedure; Continfect: Direct contact with infected persons; Lowfliud: Low fluid intake; Noncotund: Non-cotton underwear; Lackvoid: Lack of voiding.

\section{Acknowledgements}

We appreciate the efforts of all our research assistants who worked tirelessly during data collection and analysis.

\section{Authors' contributions}

Faith-Michael Uzoka led the research, supervised data collection, contributed significantly to analysis, and contributed to the writing of the methodology and results sections of the paper. Christie Akwaowo contributed significantly to the paper refinement and the discussion and conclusion sections. Chinyere Nwafor Okoli contributed significantly to the literature review section.Victory Ekpin contributed to the discussion and conclusion sections. Chukwudi Nwokoro participated in data analysis and contributed to the results section. Mohamed El Hussein contributed to the literature review and study limitations. He also did the final paper edit. Joseph Osuji contributed to the introduction and conclusion sections. Flora Aladi contributed to the introduction section. Boluwaji Akinnuwesi contributed to the literature review section. Temitope Funmilola Akpelishi contributed to the introduction section. The author(s) read and approved the final manuscript.

\section{Funding}

The funding for this research was received from the Faculty of Science and Technology Innovation Fund and the Research Grant Fund of Mount Royal University, Calgary. The funding body provided funs for study design, data collection, analysis and interpretation of data. We thank Mount Royal University, Calgary for funding this research.

\section{Availability of data and materials}

The datasets used and/or analysed during the current study are available from the corresponding author on reasonable request.

\section{Declarations}

\section{Ethics approval and consent to participate}

Ethics approval for this study was obtained from the Mount Royal University, Calgary Human Research Ethics Board; Number: 100038. We have also provided the survey (including the recruitment script), which shows the written consent to participate in the study. All participants provided written consent to participate in the study.

\section{Consent for publication}

Not applicable.

\section{Competing interests}

The authors hereby declare that there are no competing interests.

\section{Author details}

'Dept. of Math and Computing, Mount Royal University, 4825 Mt Royal Gate SW, Calgary, AB T3E 6K6, Canada. ${ }^{2}$ Dept. of Public Health, University of Uyo Teaching Hospital, Uyo, Nigeria. ${ }^{3}$ Canadian Institute for Innovation and Development, Calgary, Canada. ${ }^{4}$ Morat Medical Centre, Benin City, Nigeria. ${ }^{5}$ Dept of Computer Science, University of Uyo, Uyo, Nigeria. ${ }^{6}$ School of Nursing, Mount Royal University, Calgary, Canada. ${ }^{7}$ School of Nursing, Mount Royal University, Calgary, Canada. ${ }^{8}$ Health Watch Medical Clinic, Calgary, Canada. ${ }^{9}$ Dept of Computer Science, University of Eswatini, Kwaluseni, Eswatini. ${ }^{10} \mathrm{Health}$ Centre, Bells University of Technology, Otta, Nigeria.

Received: 7 March 2021 Accepted: 22 November 2021

Published online: 11 December 2021

\section{References}

1. WHO EMRO. Neglected tropical diseases [Internet]. 2020 [cited 2020 Nov 20]. Available from: http://www.emro.who.int/health-topics/tropicaldiseases/

2. Uzoka F-ME, Akinnuwesi BA, Amoo T, Aladi F, Fashoto S, Olaniyan M, et al. A framework for early differential diagnosis of tropical confusable diseases using the fuzzy cognitive map engine. World Academy of Science, Engineering and Technology, International Journal of Computer, Electrical, Automation, Control and Information Engineering. 2016;10(2):346-53.

3. Obot OU, Inyang UG, Osuji J, Uzoka F-ME. A hybrid methodology for differential diagnosis of confusable diseases. Journal of Health \& Medical Informatics [Internet]. 2014 [cited 2020 Nov 20]; Available from: https:// www.hilarispublisher.com/proceedings/a-hybrid-methodology-for-diffe rential-diagnosis-of-confusable-diseases-2408.html

4. Lim SS, Vos T, Flaxman AD, Danaei G, Shibuya K, Adair-Rohani H, et al. A comparative risk assessment of burden of disease and injury attributable to 67 risk factors and risk factor clusters in 21 regions, 1990-2010: a systematic analysis for the global burden of disease study 2010. Lancet. 2012;380(9859):2224-60.

5. Murray CJ, Lopez AD. Global mortality, disability, and the contribution of risk factors: global burden of disease study. Lancet. 1997;349(9063):1436-42.

6. Vos T, Lim SS, Abbafati C, Abbas KM, Abbasi M, Abbasifard M, et al. Global burden of 369 diseases and injuries in 204 countries and territories, 1990-2019: a systematic analysis for the global burden of disease study 2019. Lancet. 2020;396(10258):1204-22.

7. $\mathrm{CSDOH}, \mathrm{WHO}$. Closing the gap in a generation : health equity through action on the social determinants of health : final report of the commission on social determinants of health [internet]. Geneva, Switzerland; 2008 [cited 2021 Apr 30]. Available from: https://apps.who.int/iris/handle/ 10665/43943

8. Abossie A, Yohanes T, Nedu A, Tafesse W, Damitie M. Prevalence of malaria and associated risk factors among febrile children under five years: a cross-sectional study in Arba Minch Zuria District. South Ethiopia Infect Drug Resist. 2020;13:363-72.

9. Henry J. Tropical And Equatorial Climates. Encyclopedia of World Climatology. 2005:742-50.

10. Mogasale VV, Ramani E, Mogasale V, Park JY, Wierzba TF. Estimating typhoid fever risk associated with lack of access to safe water: a systematic literature review. J Environ Public Health. 2018;2018:9589208.

11. Deksissa T, Gebremedhin EZ. A cross-sectional study of enteric fever among febrile patients at ambo hospital: prevalence, risk factors, comparison of Widal test and stool culture and antimicrobials susceptibility pattern of isolates. BMC Infect Dis. 2019;19(1):288.

12. Tallon AK, Hill SR, Ignell R. Sex and age modulate antennal chemosensory-related genes linked to the onset of host seeking in the yellow-fever mosquito. Aedes aegypti Scientific Reports. 2019 Jan 10;9(1):43.

13. Socan M, Berginc N, Lajovic J. Varicella susceptibility and transmission dynamics in Slovenia. BMC Public Health. 2010;10:360.

14. van Rijckevorsel GGC, Damen M, Sonder GJ, van der Loeff MFS, van den Hoek A. Seroprevalence of varicella-zoster virus and predictors for seronegativity in the Amsterdam adult population. BMC Infect Dis. 2012;12:140.

15. WHO. Varicella. World health organization. 2018;

16. Eke CB, Ogbodo SO, Ukoha OM, Ibekwe RC, Asinobi IN, Ikefuna AN, et al. Seroprevalence and risk factors of hepatitis $B$ virus infection among adolescents in Enugu. Nigeria J Trop Pediatr. 2015;61 (6):407-13.

17. Dovjak M, Kukec A. Identification of health risk factors and their parameters. In: Dovjak M, Kukec a, editors. Creating healthy and Sustainable buildings: an assessment of health risk factors [internet]. Cham: springer international publishing; 2019 [cited 2020 Nov 21]. p. 83-120. Available from: https://doi.org/10.1007/978-3-030-19412-3_3.

18. Uzoka F-ME, Ndzinge T. Empirical analysis of biometric technology adoption and acceptance in Botswana. J Syst Softw. 2009 Sep 1;82(9):1550-64.

19. Federal Ministry of Health. National policy on Integrated Disease Surveillance Response in Nigeria. Abuja: Federal Ministry of Health. 2005;1-7.

20. Isere EE, Fatiregun AA, Ajayi IO. An overview of disease surveillance and notification system in Nigeria and the roles of clinicians in disease outbreak prevention and control. Niger Med J. 2015;56(3):161-8.

21. FMOH, NCDC. National Technical Guidelines for Integrated Disease Surveillance and Response [Internet]. FMOH; 2019 [cited 2021 Apr 30]. 
Available from: https://ncdc.gov.ng/themes/common/docs/protocols/ 242_1601639437.pdf

22. Ibrahim LM, Stephen M, Okudo I, Kitgakka SM, Mamadu IN, Njai IF, et al. A rapid assessment of the implementation of integrated disease surveillance and response system in Northeast Nigeria, 2017. BMC Public Health [Internet]. 2020 May 1 [cited 2021 Apr 30];20(1):600. Available from: https://doi.org/10.1186/s12889-020-08707-4.

23. Motilewa OO, Akwaowo CD, Ekanem AM. Assessment Of Implementation Of Integrated Disease Surveillance And Response In Akwa Ibom State Nigeria. Ibom Medical Journal [Internet]. 2016 [cited 2021 Apr 30];8(1):23-7. Available from: https://ibommedicaljournal.org/asses sment-of-implementation-of-integrated-disease-surveillance-and-respo nse-in-akwa-ibom-state-nigeria/

24. Mordi RM, Burke ME, Odjadjare EE, Enabulele SA, Umeh OJ. Prevalence of urinary tract infections (UTI) among pregnant women in University of Benin teaching hospital (UBTH) Benin City. Nigeria Journal of Asian Scientific Research. 2015;5(4):198-204.

25. John AS, Mboto Cl, Agbo B. A review on the prevalence and predisposing factors responsible for urinary tract infection among adults. European Journal of Experimental Biology [Internet]. 2016 Sep 20 [cited 2020 Nov 26];6(4). Available from: https://www.imedpub.com/abstract/a-reviewon-the-prevalence-and-predisposing-factors-responsible-for-urinarytract-infection-among-adults-11526.html

26. WHO. The "World malaria report 2019 " at a glance [Internet]. 2019 [cited 2020 Nov 26]. Available from: https://www.who.int/news-room/featurestories/detail/world-malaria-report-2019

27. Mohammadkhani M, Khanjani N, Bakhtiari B, Sheikhzadeh K. The relation between climatic factors and malaria incidence in Kerman, south east of Iran. Parasite Epidemiology and Control. 2016;1 (3):205-10.

28. Thang ND, Erhart A, Speybroeck N, Hung LX, Thuan LK, Hung CT, et al. Malaria in Central Vietnam: analysis of risk factors by multivariate analysis and classification tree models. Malar J. 2008 Jan 30;7(1):28.

29. Azzarri C, Signorelli S. Climate and poverty in Africa south of the Sahara. World Dev. 2020 Jan 1;125:104691.

30. De Silva PM, Marshall JM. Factors Contributing to Urban Malaria Transmission in Sub-Saharan Africa: A Systematic Review [Internet]. Vol. 2012, Journal of Tropical Medicine. Hindawi; 2012 [cited 2020 Nov 19]. p. e819563. Available from: https://www.hindawi.com/journals/jtm/2012/819563/

31. NBS \& UNICEF and UNCF (UNICEF). 2017 Multiple Indicator Cluster Survey 2016-17, Survey Findings Report [Internet]. Abuja, Nigeria: National Bureau of Statistics; 2018 [cited 2021 Jan 22]. (Multiple Indicator Cluster Survey(MICS)). Available from: https://www.jhsph.edu/ivac/wp-content/ uploads/2018/04/Nigeria-NICS-National-Brief.pdf

32. Hosoglu S, Celen MK, Geyik MF, Akalin S, Ayaz C, Acemoglu H, et al. Risk factors for typhoid fever among adult patients in Diyarbakir. Turkey Epidemiol Infect. 2006 Jun;134(3):612-6.

33. Alba S, Bakker MI, Hatta M, Scheelbeek PFD, Dwiyanti R, Usman R, et al. Risk factors of typhoid infection in the Indonesian archipelago. PLoS One. 2016;11(6):e0155286

34. Akuu JA, Danyi D, Dapaah C. Factors associated with poor food safety compliance among street food vendors in the Techiman municipality of Ghana. Afr J Food Sci. 2017;11(3):50-7.

35. Okojie PW, Isah EC. Sanitary Conditions of Food Vending Sites and Food Handling Practices of Street Food Vendors in Benin City, Nigeria: Implication for Food Hygiene and Safety [Internet]. Vol. 2014, Journal of Environmental and Public Health. Hindawi; 2014 [cited 2020 Nov 19]. p. e701316. Available from: https://www.hindawi.com/journals/jeph/2014/ 701316/

36. Midekisa A, Beyene B, Mihretie A, Bayabil E, Wimberly M. Seasonal associations of climatic drivers and malaria in the highlands of Ethiopia. Parasit Vectors. 2015;8:339-9.

37. Momoh J, Opaluwah A, Albeera H. Challenges Facing Nigeria's Urban Environment: The Abuja Case. :16.

38. Muhammed, Sabiu S, Khalii M. AN OVERVIEW OF URBANIZATION AND ITS CHALLENGES ON SUSTAINABLE DEVELOPMENT IN NIGERIA. Dutse Journal of Pure and Applied Sciences 1(1) June 2015. 2015 Sep 10;1:19-29.

39. Pinsent A, Read JM, Griffin JT, Smith V, Gething PW, Ghani AC, et al. Risk factors for UK plasmodium falciparum cases. Malar J. 2014;13(1):298

40. Amiri FN, Rooshan MH, Soliamani MJ. Hygiene practices and sexual activity associated with urinary tract infection in pregnant women. EMHJ
[Internet]. 2009 [cited 2020 Nov 19];15(1). Available from: http://www. emro.who.int/emhj-volume-15-2009/volume-15-issue-1/article11.html

41. Raoult D, Foucault C, Brouqui P. Infections in the homeless. Lancet Infect Dis. 2001;1(2):77-84.

42. Badiaga S, Raoult D, Brouqui P. Preventing and controlling emerging and reemerging transmissible diseases in the homeless. Emerg Infect Dis. 2008:14(9):1353-9.

43. Salez N, Benkouiten S, Sekene B, Charrel R, Brouqui P. Respiratory viruses within homeless shelters in Marseille. France BMC Research Notes. 2014;7:81.

44. Mackey MA, Ali MRK, Austin LA, Near RD, El-Sayed MA. The Most effective gold Nanorod size for Plasmonic Photothermal therapy: theory and in vitro experiments. J Phys Chem B. 2014;118(5):1319-26.

45. Ooi GL, Phua KH. Urbanization and slum formation. J Urban Health. 2007;84(S1):27-34.

46. Eastwood R, Lipton M. Pro-poor Growth and Pro-growth Poverty Reduction: Meaning, Evidence, and Policy Implications. :37.

47. Alawode GO, Adewole DA. Assessment of the design and implementation challenges of the National Health Insurance Scheme in Nigeria: a qualitative study among sub-national level actors, healthcare and insurance providers. BMC Public Health. 2021;21(1):124.

\section{Publisher's Note}

Springer Nature remains neutral with regard to jurisdictional claims in published maps and institutional affiliations.

Ready to submit your research? Choose BMC and benefit from

- fast, convenient online submission

- thorough peer review by experienced researchers in your field

- rapid publication on acceptance

- support for research data, including large and complex data types

- gold Open Access which fosters wider collaboration and increased citations

- maximum visibility for your research: over $100 \mathrm{M}$ website views per year

At BMC, research is always in progress.

Learn more biomedcentral.com/submissions 